\title{
On the use of the push-pull cannula as a means of measuring biochemical changes during ongoing behavior ${ }^{1}$
}

H. A. TILSON and S. B. SPARBER, UNIVERSITY OF MINNESOTA, Minneapolis, Minnesota 55455

Chronic indwelling push-pull cannulae (Gaddum, 1961) were implanted in the right lateral ventricles of two adult male and two adult female rats. Perfusion with artifical cerebrospinal fluid containing trace amounts of tritiated norepinephrine $\left(H^{3}-7-N E\right)$ was performed, under pentobarbital anesthesia, at rates of 20,40, and $70 \mathrm{microl} / \mathrm{min}$ with two male rats and 40 and $70 \mathrm{microl} / \mathrm{min}$ with the female rats. Aliquots of perfusate were counted in order to determine if $H^{3}$ from $H^{3}-7-N E$ varied as a function of perfision rate, and volume loss, if any, was monitored by weighing tared collection vials. Perfusion of the male rats at $20 \mathrm{microl} / \mathrm{min}$ while they were working for food under fixed-ratio schedules of reinforcment indicated that this method might be used to study central biochemical-behavioral interactions using operant-conditioning procedures.

The problem of introducing substances into the brain in quantifiable amounts has been difficult to overcome, especially if the substances do not readily pass from the peripheral circulation to the brain, i.e., blood-brain barrier (Levin \& Scicli, 1969). Determining the effects of alteration of biogenic amines upon behavior usually has been accomplished by peripheral administration of drugs known to alter the synthesis, uptake, binding, or metabolism of endogenous amine stores. Scheckel and Boff (1964), for example, were able to conclude on the basis of such a technique that a selective reduction or release of brain norepinephrine (NE) was associated

Fig. 1. Push-Pull Cannula. The base consisting of a brass portion having male screw threads into which the outer concentric stainless steel tube is soldered, is implanted with the aid of acrylic cement (A). The stylus bead (C) is screwed into place and after the recovery period, is removed and replaced with the perfusion cap (B), which contains the inner concentric steel tube. This tube is continuous and protrudes $0.5 \mathrm{~mm}$ from the outer tube into the brain. A second short tube, which stops just inside the cap, is used to withdraw (pull) the perfusion solution up through the outer implanted tube. with behavioral stimulation. There are, however, limitations concerning interpretation of data derived from such procedures. For example, it has been shown that NE, when given so that it passes the blood-brain barrier (intraventricularly or intravenously into animals with immature blood-brain barriers), produces behavioral depression (Spooner \& Winters, 1966; Marley, 1966; Mandell \& Spooner, 1968). Furthermore, since regional distribution studies have found unequal concentrations of biogenic amines (Glowinski \& Axelrod, 1966; Glowinski, Axelrod, \& Iverson, 1966), the major site of action in the central nervous system is not easily determined for substances producing behavioral changes associated with general alteration of biogenic amines. A system that could monitor biochemical changes occurring in a specific locus during a given behavioral sequence is needed. Perfusion of the cerebral ventricles (Bhattacharya \& Feldberg, 1958) might be used in conjunction with operant-conditioning procedures to measure more precisely biochemical-behavioral changes under physiologic conditions. Such a perfusion method involves movement of fluid throughout the ventricular system. The push-pull cannula (PPC) (Gaddum, 1961), however, allows for perfusion of more localized areas. Biochemical studies using the PPC have been reported, and most use anesthetized Ss (Mitchell \& Szerb, 1962;
McLennan, 1964; Chase \& Kopin, 1968) Recently, the PPC has been used to study the release of suspected neurotransmitters from specific areas of the brain as related to electrical stimulation of "reward centers," and to investigate the effects of peripheral administration of amphetamine (Stein \& Wise, 1967, 1969). One parametric study (Szerb, 1967) reports on the effects of rate of perfusion, protrusion of the inner from the outer tube, and diameter of tubing of cannulae implanted in $1 \%$ agar gel. The present report deals with an extension of the in vitro model experiments of Szerb (1967) in studying some of the parameters of perfusion on the lateral ventricle of the rat.

\section{EXPERIMENT 1}

In the first study, the evaluation of optimal conditions for perfusion with the PPC consisted of determining the loss of tritiated $\mathrm{NE}\left(\mathrm{H}^{3}-\mathrm{NE}\right)$ during perfusion of the lateral ventricle. $\mathrm{H}^{3}-\mathrm{NE}$ was used because it is a normal constituent of brain (CSF), and the radioactive isotope allowed for simple and rapid determination of trace concentrations.

\section{Method}

Implantation. The right lateral ventricle of four 200-day-old Holtzman rats, two males and two females, were implanted with chronic-indwelling PPC (Fig. 1). The PPC consisted of two concentric stainless

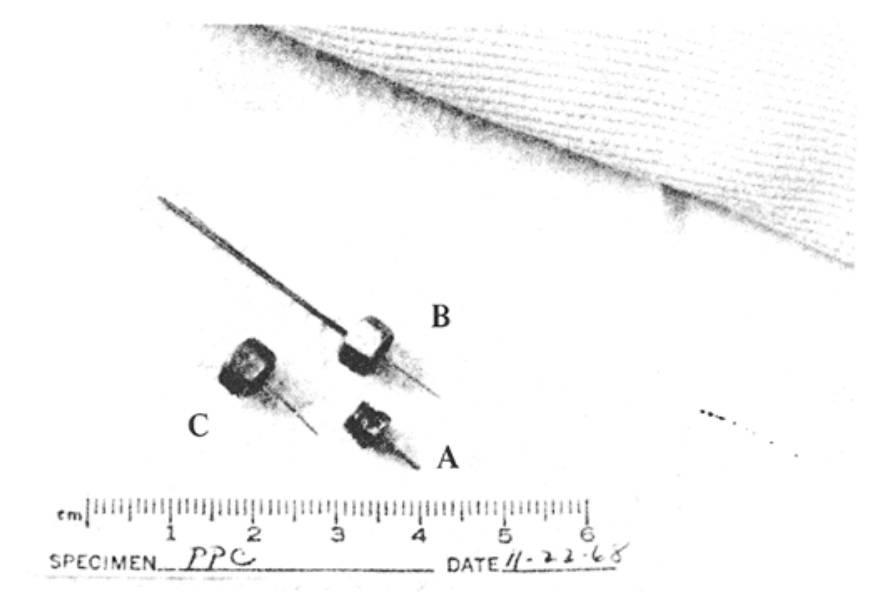


needle tubes ( 28 and 22 gauge) mounted in a brass screw head with the inner needle protruding $0.5 \mathrm{~mm}$ into the brain. Ventricular implantation was performed under sodium pentobarbital anesthesia ( $40 \mathrm{mg} / \mathrm{kg}$ ). Coordinates were determined by measuring $1 \mathrm{~mm}$ posteriorally and $1 \mathrm{~mm}$ laterally from the bregma (Noble, Wurtman, \& Axelrod, 1967). The tip of the PPC was lowered $3.25 \mathrm{~mm}$ from the skull into the brain through a small hole drilled with a dental burr. Two small anchor screws were placed near the cannula, and the entire unit anchored in place with acrylic dental cement. The stylus was placed in the implanted unit, and Ss were allowed to recover at least 5 days before perfusions were performed.

Perfusion. Ss were anesthetized with sodium pentobarbital. The stylus was removed from the implanted area (Fig. 1), and the perfusion unit with attached polyethylene leads was inserted. They were placed inside an incubator maintained at $37^{\circ} \mathrm{C}$ because of reports that central biogenic amines might have a role in thermoregulatory mechanisms (Feldberg \& Myers, 1963). Temperature of the Ss was recorded with a Yellow Springs rectal probe (Model 43TD). Perfusion was accomplished by means of a Harvard infusion-withdrawal pump (Model 906). Samples were collected in a vial placed between the withdrawal syringe and the $S_{s}$ (Fig. 2). The two males were each perfused once at the rate of 70,40 , and 20 $\mathrm{microl} / \mathrm{min}$. The two females were each perfused at rates of 70 and $40 \mathrm{microl} / \mathrm{min}$. Collection periods were every $5 \mathrm{~min}$ for rates of 70 and $40 \mathrm{microl} / \mathrm{min}$; the duration of the session was $50 \mathrm{~min}$. Samples were collected every $8 \mathrm{~min}$ for the $20 \mathrm{microl} / \mathrm{min}$ rate, and the session was terminated after $48 \mathrm{~min}$.

The perfusion solution consisted of trace amounts of $\mathrm{H}^{3}-\mathrm{NE}$ (New England Nuclear, Boston, Mass.) in artificial cerebrospinal fluid (art. csf) (Robinson, Cutler, Lorenzo, \& Barlow, 1968). Concentration of $\mathrm{H}^{3}$-NE was $.008 \mathrm{mg} / \mathrm{ml}$ for perfusions at $70 \mathrm{microl} / \mathrm{min}$ and $.012 \mathrm{mg} / \mathrm{ml}$ for perfusions at 20 and 40 $\mathrm{microl} / \mathrm{min}$. The perfusion medium was kept at approximately $37^{\circ} \mathrm{C}$.

Each experimental session had two timed control periods, one in the beginning and one at the end. The csf solution was weighed after infusion into tared vials through the center (push) tube of the cannula. The average weight of csf of the

Fig. 2. Rat with perfusion cap inserted and polyethylene tubing leading to a trap (collection vial) between withdrawal syringe and brain. two control periods was used to determine the percentage of solution recovered during the perfusion periods. Ten microliter aliquots were taken from each of the samples and controls and added to counting vials containing $10 \mathrm{ml}$ of Bray's solution (1960). These were counted in a Beckman (Model DPM-100) scintillation spectrometer preset to count long enough to insure a counting error of not more than $1 \%$. The percentage recovery of counts collected for each sample was calculated by dividing the number of counts of each perfusion sample by the mean value of the two control periods.

Following the experiment, confirmation of the placement of the PPC in the ventricles of the females was determined by injecting 5 microliters of dye through the smaller tube. The Ss were then decapitated and the brains quickly removed. Examination of the brains revealed the presence of dye in the right ventricle of each $S$.

\section{Results}

Figure 3 shows the mean percent recovery of counts for each sample as a function of the three rates of perfusion. For the rate of $20 \mathrm{microl} / \mathrm{min}$, recovery of counts does not fall below $94 \%$. For the $40 \mathrm{microl} / \mathrm{min}$ rate, the first 5 -min sample contained $85 \%$ of control samples with subsequent samples varying between $95 \%$ and $99 \%$. The $70 \mathrm{microl} / \mathrm{min}$ rate resulted in recoveries of $65 \%$ and $62 \%$ for the first two samples, respectively, with the following samples varying from 94-98\%. Figure 4 shows mean percent recovery of weight. All three perfusion rates resulted in volume recoveries of between $91 \%$ and $98 \%$.

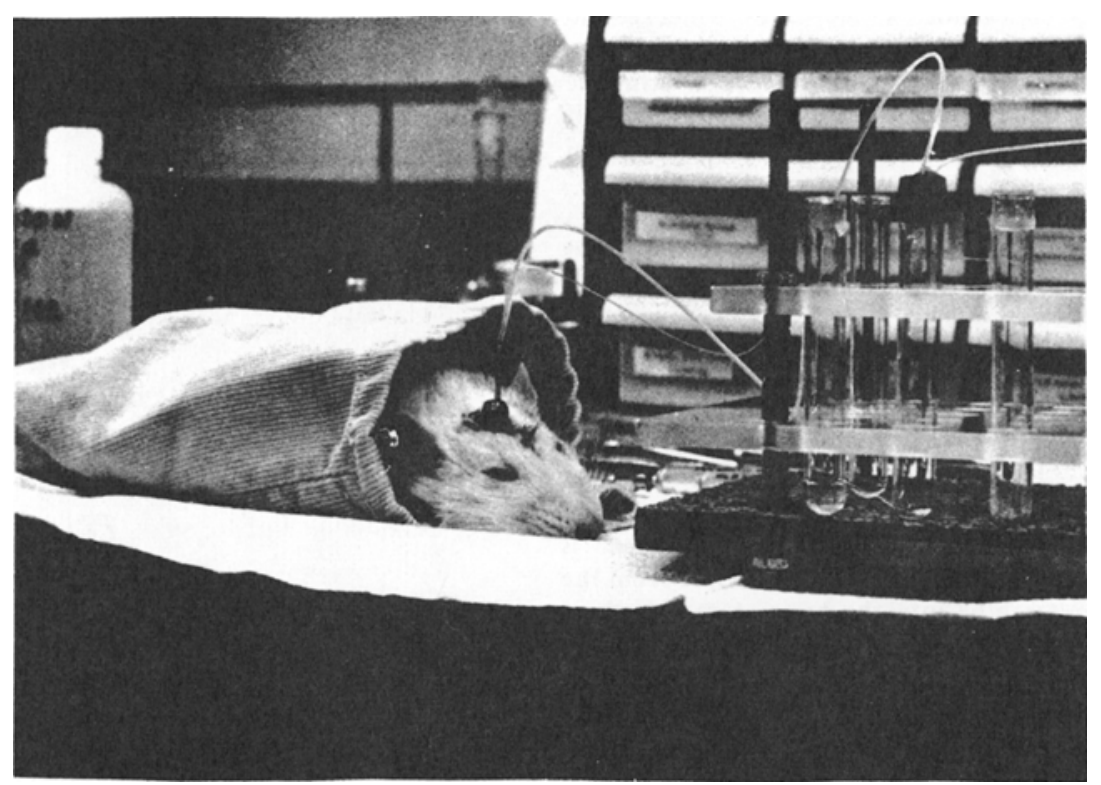

\section{Discussion}

It is apparent from Figs. 3 and 4 that loss of counts was not the result of volume loss. For example, the greatest loss of counts for the $70 \mathrm{microl} / \mathrm{min}$ rate occurred in the first two 5 -min periods. There was not, however, a corresponding loss of volume during the collection of these two samples. This strongly suggests that initial diffusion and dilution with endogenous ventricular fluid may have occurred as a result of eddy currents produced at higher perfusion rates. Another possible explanation for these data is that the area of perfusion may have been greater with higher rates allowing initial uptake of $\mathrm{H}^{3}$-NE by the ventricles (Glowinski \& Axelrod. 1966).

\section{EXPERIMENT 2}

As with most studies in the literature, the data of Experiment I were taken from Ss under anesthesia, allowing little opportunity to observe behavioral effects of the perfusion technique. An operant-conditioning situation was incorporated to determine if the perfusion operation would have any disruptive effects upon on-going behavior.

\section{Method}

Both of the male PPC-implanted rats were maintained at $80 \%$ ad lib body weight. Water was always available in the $\mathrm{Ss}^{3}$ cage, but not in the experimental chamber. Ss were individually housed in a room with a 12-h light-dark cycle and with relatively constant temperature and humidity.

Ss were trained to press a bar for food in an operant-conditioning box enclosed 


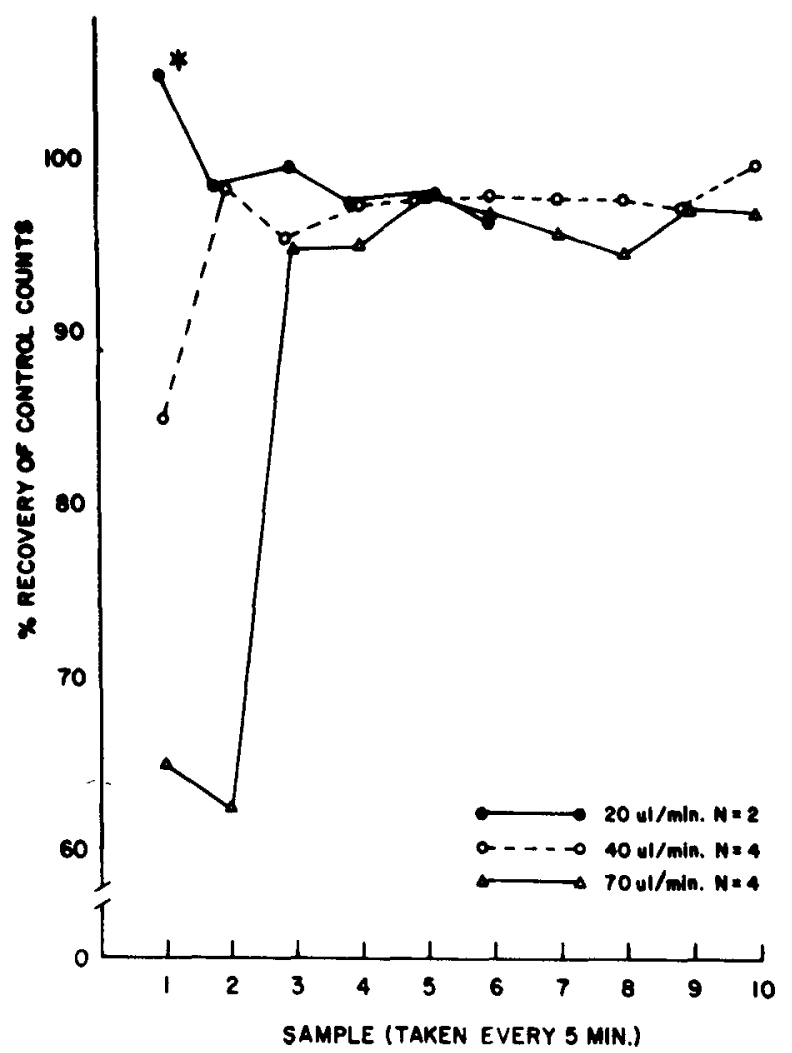

Fig. 3. Mean percent recovery counts for each sample as a function of rate of perfusion. Samples were taken every $5 \mathrm{~min}$ for rates of 40 and $70 \mathrm{microl} / \mathrm{min}$. Asterisk indicates that samples were taken every $8 \mathrm{~min}$ for $20 \mathrm{microl} / \mathrm{min}$ rate.

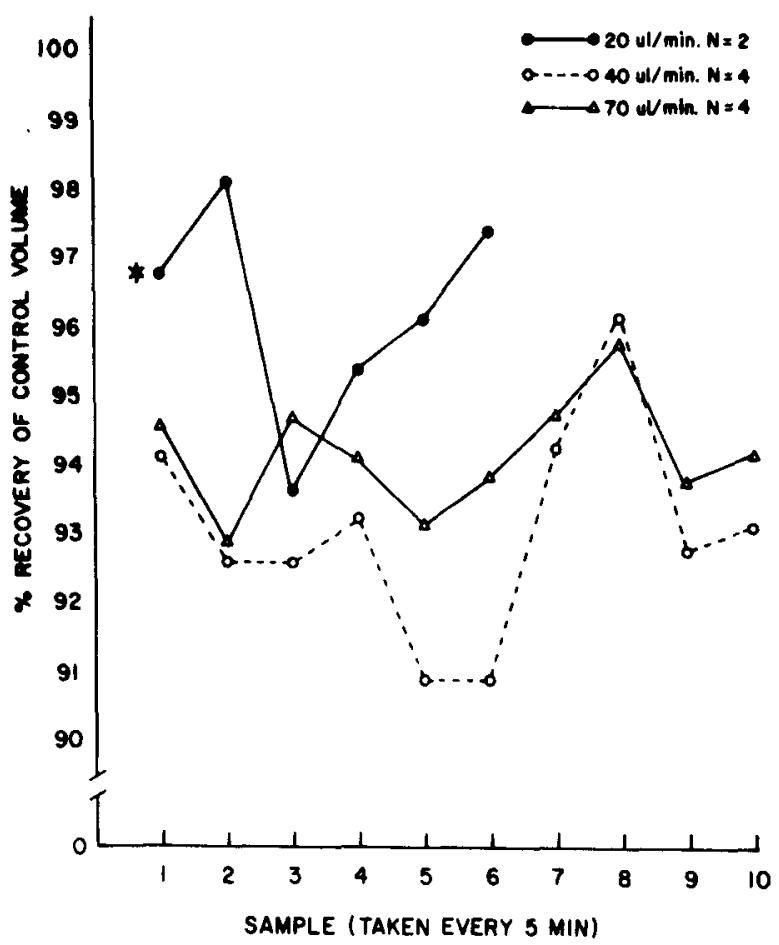

Fig. 4. Mean percent recovery of weight for each sample as a function of rate of perfusion. Samples were taken every $5 \mathrm{~min}$ for rates of 40 and $70 \mathrm{microl} / \mathrm{min}$. Asterisk indicates that samples were taken every $8 \mathrm{~min}$ for $20 \mathrm{microl} / \mathrm{min}$ rate. within a sound-attenuated chamber equipped with a sound generator to mask external noise. Programming of reinforcements and recording of responses were done automatically with relay-type equipment. Noyes food pellets $(45 \mathrm{mg})$

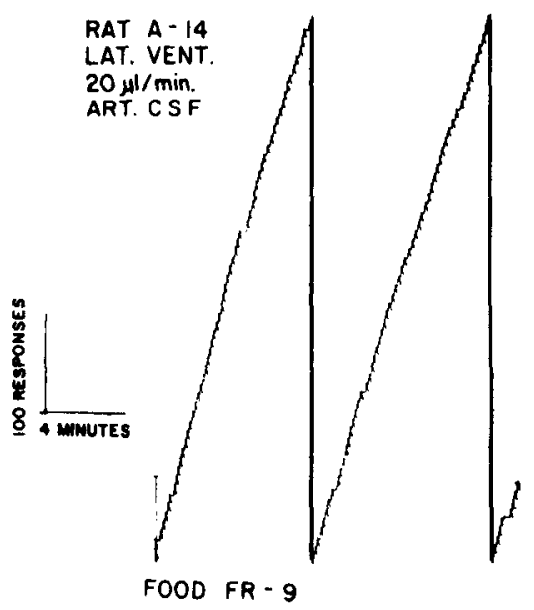

Fig. 5. Sample cumulative record of Rat A-14 working for food reinforcement while having its ventricle perfused with art. csf. Duration of session was $20 \mathrm{~min}$. were used as reinforcers on a low fixed-ratio schedule of reinforcment (FR 9) until a steady baseline of behavior was established. Ss were then habituated to having the stylus removed and the perfusion unit with polyethylene leads attached to the implanted base. As the Ss bar-pressed for food, their lateral ventricles were perfused with artificial cerebrospinal fluid. Sessions were terminated at the end of $20 \mathrm{~min}$. The perfusion consisted of drawing the perfusate directly into the withdrawal syringe. Rate of perfusion was $20 \mathrm{microl} / \mathrm{min}$.

\section{Results and Discussion}

Figure 5 shows a representative cumulative record of bar-pressing for food reinforcement of one $S$ while being perfused. The rate of responding for both Ss following habituation to the procedure of perfusion was comparable to baseline performance. Ferster and Skinner (1957) have noted that novel stimuli have a characteristic impairment on response rate, and repeated introduction (loss of novelty) of such stimuli eventually results in return to baseline performance. These data indicate that operant behavior can occur simultaneously with the operation of the PPC with no apparent effect upon responding.

\section{REFERENCES}

BHATTACHARYA, B., \& FELDBERG, W. Perfusion of cerebral ventricles: Effects of drugs on outflow from the cisterna and aqueduct. British Journal of Pharmacology, $1958,13,156-162$.

BRAY, B. A. A simple efficient liquid scintillator for counting aqueous solutions in a liquid scintillation counter. Analytic Biochemistry, $1960,1,279-285$

CHASE, T. N., \& KOPIN, I. J. Stimulus-induced release of substances from olfactory bulb using the push-pull cannula. Nature, 1968, $217,466-467$

FELDBERG, W., \& MYERS, R. A new concept of temperature regulation by amines in the hypothalamus. Nature, 1963, 200, 1325.

FERSTER, C. B., \& SKINNER, B. F. Schedules of reinforcement. New York: AppletonCentury-Crofts, 1957.

GADDUM, J. Push-pull cannulae. Journal of Physiology, 1961, 155, 1P-2P.

GLOWINSKI, W., \& AXELROD, J. Effects of drugs on the disposition of $\mathrm{H}^{3}$-norepinephrine in the rat brain. Pharmacological Review, $1966,18,775-785$.

GLOWINSKI, W., AXELROD, J., \& IVERSON, L. Regional studies of catecholamines in the rat brain. IV. Effects of drugs on the disposition and metabolism of $\mathrm{H}^{3}$-norepinephrine and $\mathrm{H}^{3}$-dopamine. Journal of Pharmacology \& Experimental Therapeutics, 1966, 153, 30-41.

LEVIN, E., \& SCICLI, G. Brain barrier phenomenon. Brain Research, 1969, 13, 1-12.

MARLEY, E. Behavioral and electrophysiological effects of catecholamines. Pharmacological Review, 1966, 18, 753-768. 
MANDELL, A. J., \& SPOONER, C. E. Psychochemical research studies in man. Science, 1968, 162, 1442-1453.

MCCLENNAN, H. The release of acetylcholine and of 3-hydroxytyramine from the caudate nucleus. Journal of Physiology, 1964, 174, 152-161.

MITCHELL, J., \& SZERB, J. Abstract XXII. International Physiological Congress, 1962, No. 819.

NOBLE, E. P., WURTMAN, R. J., \& AXELROD, J. A simple and rapid method for injecting $\mathrm{H}^{3}$-norepinephrine into the lateral ventricle of the rat brain. Life Sciences, 1967, 6, 281-291.

ROBINSON, R., CUTLER, W., LORENZO, A., \&
BARLOW, C. Transport of sulfate, thiosulfate and iodide by choroid plexus in vitro. Joumal of Neurochemistry, 1968, 15, 1169-1179.

SCHECKEL, C. L., \& BOFF, E. Behavioral stimulation in rats associated with a selective release of brain norepinephrine. Archives of International Pharmacodynamics, 1964, 152, 479-490.

SPOONER, C. E., \& WINTERS, W. D Neuropharmacological profile of the young chick. International Journal of Neuropharmacology, 1966, 5, 217-236.

STEIN, L., \& WISE, C. Release of hypothalamic norepinephrine by rewarding electrical stimulation in the unanesthetized rat. Federal
Proceedings, 1967, 23, 651.

STEIN, L., \& WISE, C. Release of norepinephrine from hypothalamus and amygdala by rewarding medial forebrain bundle stimulation and amphetamine. Journal of Comparative \& Physiological Psychology, 1969, 67, 189-198. SZERB, J. C. Model experiments with Gaddum's push-pull cannulas. Canadian Journal of Physiological Pharmacology, 1967, 45, 613.619.

NOTE

1 .This research was supported by National Institute of Mental Health Training Grant MH-8565. 